\title{
Design de serviços: um estudo sobre inovação em características e competências de processos para cocriação de valor
}

\section{Service Design: a study on innovation in characteristics and competencies of process for value co-creation}

\author{
Alan Felismino da Silva, Universidade Federal do Rio de Janeiro. \\ amino@coppe.ufrj.br
}

Fernando Del Caro Secomandi, Universidade do Estado do Rio de Janeiro.

fsecomandi@esdi.uerj.br

André Ribeiro de Oliveira, Universidade do Estado do Rio de Janeiro.

andre.ribeiro@eng.uerj.br

Resumo

$\mathrm{O}$ setor de serviços vem apresentando impactos econômicos significativos nos últimos anos. $\mathrm{O}$ contexto é favorável para o crescimento da área de design de serviços, a fim de melhorar a tomada de decisões do provedor de um serviço pelo ponto de vista de seus clientes. Esta pesquisa apresenta um estudo aplicado em uma academia de musculação sobre fluxogramas de processos e inovação em serviços orientado à melhoria das suas atividades. Explorando uma lacuna sobre recursos no diagrama Process Chain Network (PCN), esta pesquisa conclui que a combinação do diagrama PCN de Sampson (2015) com o quadro conceitual de características de serviços de Gallouj \& Weinstein (1997) simplifica a complexidade cognitiva do processo pela visualização de toda cadeia de serviço e alinha as expectativas dos provedores e usuários, pela análise dos recursos tangíveis, intangíveis e conhecimentos tácitos necessários para estrutura e representação visual de um serviço.

Palavras-chave: Design de Serviços, Inovação em Serviços, Design de Negócios

\begin{abstract}
The service sector presents significant economic impacts in recent years. This context is favorable for the growth of the Service Design discipline, in order to improve decision making of provider from the client's point of view about a service. This research presents a study applied in a fitness center about flowcharts and innovation in services as a way to improve its activities. Exploring a gap about resources in Process Chain Network (PCN) diagram, a visual tool for communication and analysis of a service, this research concludes that the mixing of PCN diagram by Sampson (2015) with the conceptual framework of service characteristics of Gallouj \& Weinstein (1997) simplifies the cognitive complexity of the process by visualizing the whole service chain and align the expectations of providers and users, by analyzing the tangible and intangible resources and tacit knowledge necessary for the structure and visual representation of a service.
\end{abstract}

Keywords: Service Design, Innovation in Service, Business Design

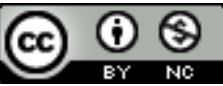




\section{Introdução}

O setor de serviços possui grande relevância para a economia de muitos países. Segundo Reason, Lovlie \& Flu (2016), os serviços podem corresponder de $70 \%$ a $80 \%$ da produção econômica de vários países.

O design de serviços é uma área de pesquisa que ganha cada vez mais espaço nos periódicos, conferências e programas educacionais (SECOMANDI \& SNELDERS, 2018). Derivado inicialmente das disciplinas de engenharia de produção e marketing e, posteriormente, recebendo contribuições relevantes da área do design industrial, o design de serviços ainda se posiciona como uma disciplina em processo de maturidade. A pesquisa científica sobre design de serviços relata diversas abordagens orientadas tanto para interesses corporativos, com vistas à inovação de produtos (FLIESS \& KLEINALTENKAMP, 2004; BATE \& ROBERT, 2007; ZEITHAML \& BITNER, 2008; PATRICIO et al, 2011; STEEN et al, 2011; CARVALHO \& GOODYEAR, 2017; BAEK et al., 2017), quanto para interesses sociais, almejando o atendimento de necessidades comuns de uma comunidade (MERONI, 2007; CIPOLLA \& MANZINI, 2009).

Em todas as abordagens, identifica-se a importância de se entender e representar visualmente não só a cadeia produtiva, mas também todo o percurso dos usuários em um serviço (ALT \& PINHEIRO, 2011; STICKDORN \& SCHNEIDER, 2014). Uma das ferramentas utilizadas é o service blueprint (SHOSTACK, 1982), que possibilita o registro de um serviço por meio de um fluxograma de processo com o objetivo de apoiar o planejamento, organização e controle de atividades sequenciais (LOVELOCK \& WRIGHT, 2006). A literatura sobre fluxogramas de processos mostra diversos formatos com pontos fortes e fracos, que variam de acordo com a finalidade da sua utilização (JORGE \& MIYAKE, 2014; FELISMINO \& SECOMANDI, 2016). O diagrama Process Chain Network - PCN, de Sampson (2015) é um modelo de fluxograma de processo recente que, além de representar visualmente um determinado serviço com foco no beneficiário final de seus processos, permite a análise dos graus de interação e das atribuições entre mais de dois atores.

A pesquisa a seguir investiga uma lacuna do método PCN, que é o mapeamento dos recursos implicados nos processos de serviço descritos por meio deste diagrama. O mapeamento de recursos técnicos (equipamentos, materiais, infraestrutura, etc.) e de competências intangíveis (conhecimentos tácitos, habilidades interpessoais, formações acadêmicas, etc.) necessários para operação das atividades de serviço, ao longo de toda a cadeia de produção, possui papel relevante no projeto do serviço. Do ponto de vista dos recursos técnicos físicos, se um serviço depende de determinado aplicativo interativo a fim de melhorar a qualidade dos resultados obtidos, deve-se prever que tal alteração demanda dos clientes (e/ou colaboradores) saber operar tal tecnologia, possuindo as devidas competências para manutenção em caso de falhas, por exemplo. O mesmo ocorre do ponto de vista de recursos intangíveis e conhecimentos tácitos. Quando um colaborador é contratado para melhorar o atendimento dos clientes, é importante poder descrever, por meio do 
diagrama PCN, quais habilidades interpessoais específicas desse operador têm um impacto na cadeia de produção do serviço em questão.

Como solução para suprir essa lacuna, este trabalho foi pautado na contribuição acadêmica de Gallouj \& Weinstein (1997) na área de economia, em que a inovação em serviços é descrita em termos da combinação entre características distintas (técnicas, competências etc.). As vantagens dessa contribuição são demonstradas neste artigo por meio de um estudo de caso em uma organização prestadora de serviço de musculação, a qual passou por uma mudança em seus processos a partir do ponto de vista dos colaboradores e usuários.

A conclusão desta pesquisa reconhece o valor das percepções e comportamentos, inesperados pelos provedores e consumidores, como essenciais para busca de inovações em um serviço, desdobrando-os em um mapeamento de recursos de diferentes naturezas sobre diferentes atividades que compõem um processo de serviço. A coleta, a exploração e o desenvolvimento do design de um serviço pela metodologia proposta simplificam a complexidade de comunicação dos recursos (físicos e/ou intangíveis) de um serviço e melhoram a compreensão do trabalho executado pelas partes interessadas. Sendo assim, se o serviço de um bar fosse o objeto de análise, seria relevante entender, por exemplo, como os usuários reduzem a espera por um serviço, e como os colaboradores aumentam a velocidade do atendimento. Esse entendimento é focado em ações não programadas e improvisadas que podem ser melhoradas por recursos técnicos (como notificações do sistema de informação do bar, via smartphone, para comunicar os usuários de uma fila sobre o momento em que há mesas disponíveis) e recursos intangíveis dos colaboradores (como o comportamento cordial dos colaboradores na recepção dos clientes, ou conhecimentos de gestão pela distribuição de aperitivos como recompensas aos clientes por tempos de espera ou falhas no serviço).

Em resumo, a pesquisa tem como objetivo geral apresentar uma metodologia que estimula a cocriação no mapeamento e análise das atividades dos processos de serviços, contribuindo assim para a área de design de serviços. Como objetivos específicos, a pesquisa busca (i) explorar as percepções dos usuários e colaboradores para gerar um serviço mais desejável e alinhado com as tendências do mercado e; (ii) facilitar a comunicação visual da cadeia produtiva de um serviço pela associação das percepções dos usuários e colaboradores passíveis de gerar melhorias nas atividades.

O artigo apresenta inicialmente uma revisão da literatura sobre design de serviços, orientada para processos de serviços, e inovação em serviços, pelo ponto de vista econômico. Em seguida é apresentado os procedimentos metodológicos desenvolvidos. Posteriormente, é apresentado o estudo de caso realizado e, na sequência, a descrição das conclusões e considerações finais do estudo. 


\section{Revisão bibliográfica}

\subsection{Design de serviços: abordagens orientadas a processos}

A inovação em serviços surge da pesquisa e criação de métodos e ferramentas que proporcionam uma melhor experiência do serviço para os clientes (BITNER et al, 2007). Shostack (1982), através de seu Service Blueprint (SB), propõe um fluxograma que representa o serviço do ponto de vista de atividades, garantindo o melhor gerenciamento do negócio e oferecendo uma melhor compreensão do que está sendo ou será produzido e/ou oferecido ao cliente. O SB possui um papel seminal na criação de novos fluxogramas de processos em serviços (FLIESS \& KLEINALTENKAMP, 2004).

Evolutivamente, verifica-se que o diagrama PCN de Sampson (2015), além de se basear nos conceitos consagrados de serviços (SAMPSON \& FROEHLE, 2006), apresenta melhorias frente ao SB que, desde a sua criação vieram ganhando importância (SAMPSON, 2015), como a representação das atividades do consumidor (EINCHENTOPF et al, 2011) e o registro da percepção de valor do serviço por múltiplos atores (PATRICIO et al, 2011).

Essas melhorias citadas são entendidas nesta pesquisa como justificativas para a escolha desse fluxograma de processo como instrumento nos estudos empíricos em detrimento de outras. Segundo Sampson (2015), o PCN nasce das limitações existentes nas técnicas de mapeamento de processos como EPC, UML, IDEF0 e BPMN (Business Process Model Notation), referentes à representação do usuário final por meio de uma interface dentro do processo produtivo, que explore não só as ações dos clientes contidos nos limites físicos da organização, mas também as relações que estão por toda a cadeia produtiva do serviço. A figura 1 apresenta as definições de todos os elementos de um diagrama PCN.

\begin{tabular}{|ll|}
\hline Elementos PCN & Definição \\
\hline Cadeia do processo & Uma sequência de passos com um propósito identificado \\
\hline Entidade do processo & Uma entidade que participa e toma decisões sobre os passos do processo \\
\hline Valor & A satisfação das necessidades de entidade de processo \\
\hline Beneficiário especifico & $\begin{array}{l}\text { Uma entidade que participa da cadeia de processo para ter suas necessidades satisfeitas por } \\
\text { competências específicas do processo }\end{array}$ \\
\hline Beneficiário genérico & $\begin{array}{l}\text { Uma entidade que participa da cadeia de processo para adquirir recursos genéricos, com } \\
\text { vistas a atender suas necessidades Dor outras cadeias de processo }\end{array}$ \\
\hline Domínio do processo & Porção da cadeia de processos que está sob controle e responsabilidade de uma entidade \\
\hline Regiões do processo & Áreas do domínio do processo para os passos de um tipo particular de interação \\
\hline Interação direta & Passos que envolvem interação entre pessoas de entidades do processo \\
\hline Interação adjacente & Passos que envolvem interação com materiais de outra entidade do processo \\
\hline Interação Independente & Passos que são realizados independentemente da intervenção de outra entidade do processo \\
\hline
\end{tabular}


O diagrama PCN auxilia na identificação de possibilidades de se inovar em atividades consideradas problemáticas, ineficientes ou difíceis, de acordo com a opinião dos usuários. Segundo Sampson (2015), quando as atividades estão localizadas na região dos clientes, verificase maior grau de flexibilidade de seu resultado, conforme o desejo dos clientes que as executam. Em contrapartida, as atividades localizadas na região do provedor apresentam maior grau de controle, resultando em economias de escala. A figura 2 apresenta um exemplo de diagrama PCN aplicado a um serviço de varejo de móveis. O diagrama lida inicialmente a partir da área do cliente (lado direito do PCN) com a atividade "Necessitar de móveis". Seguindo as setas a partir dessa atividade, em resumo, o processo ilustra as atividades necessárias para compra de um móvel em uma loja até sua entrega e uso. O processo também ilustra as atividades do provedor (lado esquerdo) relativas à produção do móvel e em seguida sua venda e entrega.

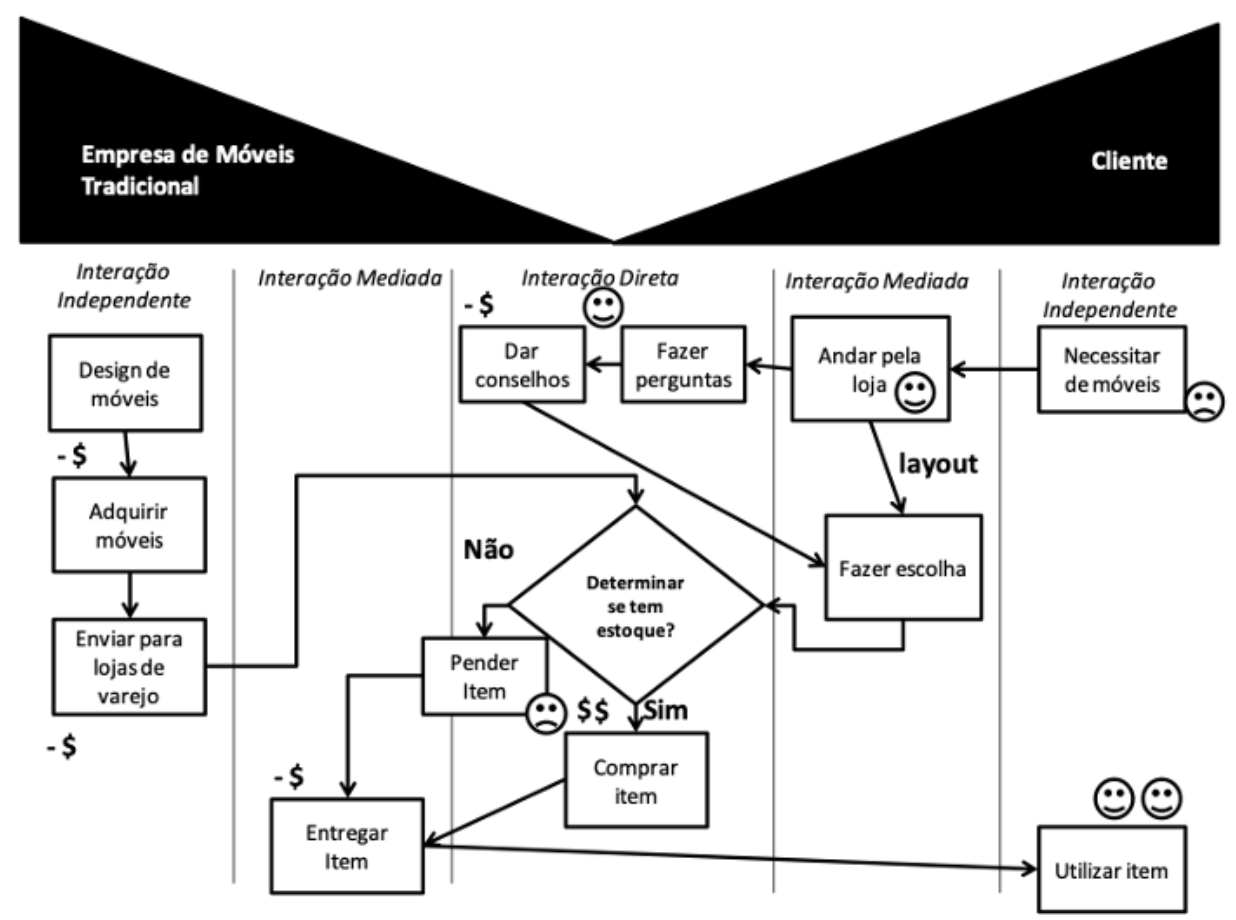

Figura 2: Diagrama PCN de uma loja de móveis. Fonte: Adaptado Sampson (2015)

Como foi visto, o diagrama PCN se baseou em conceitos já conhecidos pelo mercado para construir uma ferramenta que reduzisse a probabilidade de incerteza de sucesso em inovação em um projeto de processos de serviço. A presente pesquisa tem a mesma motivação, considerando que as contribuições sobre inovação em serviço oriundas da área da economia podem oferecer novos modos de se planejar e desenvolver projetos inovadores. Sendo assim, entende-se que o diagrama PCN pode ser complementado com contribuições advindas do trabalho de Gallouj \& Weinstein (1997). 


\subsection{Inovação em serviços: modelos econômicos baseados em características}

A inovação em serviços tem sido pesquisada de forma sólida por estudiosos da área econômica em busca de melhor conhecer seus impactos e definições (DELAUNEY \& GADREY, 1992; GADREY, 2000; ILLERIS, 2007). De acordo com Illeris (2007), a discussão referente às definições de um serviço tem uma implicação direta sobre o que seria uma forma de inovação do setor. Para muitos autores, o setor de serviços não contribui significativamente por si próprio com a inovação, apenas implanta em seus processos novas tecnologias advindas de outros setores, como o da indústria. Gallouj \& Savona (2009) consideram esse ponto de vista inadequado e concluem que tal crença se deve à falta de definições claras quanto ao que é o serviço, o que impacta a análise e medição de seus resultados.

Em resposta a essa discussão, Gallouj \& Weinstein (1997) apresentam um quadro conceitual em que as tentativas de se definir inovação em serviços ocorrem de acordo com três tipos de abordagens: a assimiladora, criada pelos pioneiros da pesquisa em economia industrial identificando elementos de serviços pelo ponto de vista dos bens materiais; a diferenciadora, defendida pelos pesquisadores que buscam ressaltar as especificidades do serviço; e, por fim, a integradora, que busca incorporar em um único quadro conceitual tanto bens como serviços, com a preocupação de se reconhecer as especificidades dos serviços e os seus aspectos não tecnológicos. A abordagem integradora é seguida nesta pesquisa sob a luz do modelo de Gallouj \& Weinstein (1997), baseado nos trabalhos de Lancaster (1966) e de Saviotti \& Metcalfe (1984).

Gallouj \& Weinstein (1997) definiram os seguintes elementos constitutivos de um serviço (Figura 3): características técnicas tangíveis (softwares, computadores, equipamentos etc.); intangíveis do provedor do serviço; [Xi] (expertise em vendas, instruções de trabalho, normas operacionais etc.) e tácitos como competências do provedor [Ci] (formação em ciências contábeis e facilidade com matemática em um escritório contábil); características do serviço [Yi] (satisfação alimentar em um restaurante, realização de melhorias estéticas em um salão de beleza etc.); competências dos clientes [C'] (habilidades psicológicas e motoras, compreensão sobre funcionamento de equipamentos, reconhecimento de materiais e produtos etc.).

Devido a avanços tecnológicos impactando a participação de clientes em processos de serviços, De Vries (2006) introduziu em seguida um novo vetor definido como características técnicas do cliente [X'] (equipamentos como smartphones, tablets, cartões eletrônicos etc.), relacionado aos serviços automatizados como caixas eletrônicos, aplicativos, entre outros. A figura 3 mostra o modelo de características de Gallouj \& Weinstein (1997), adaptado por De Vries (2006) 


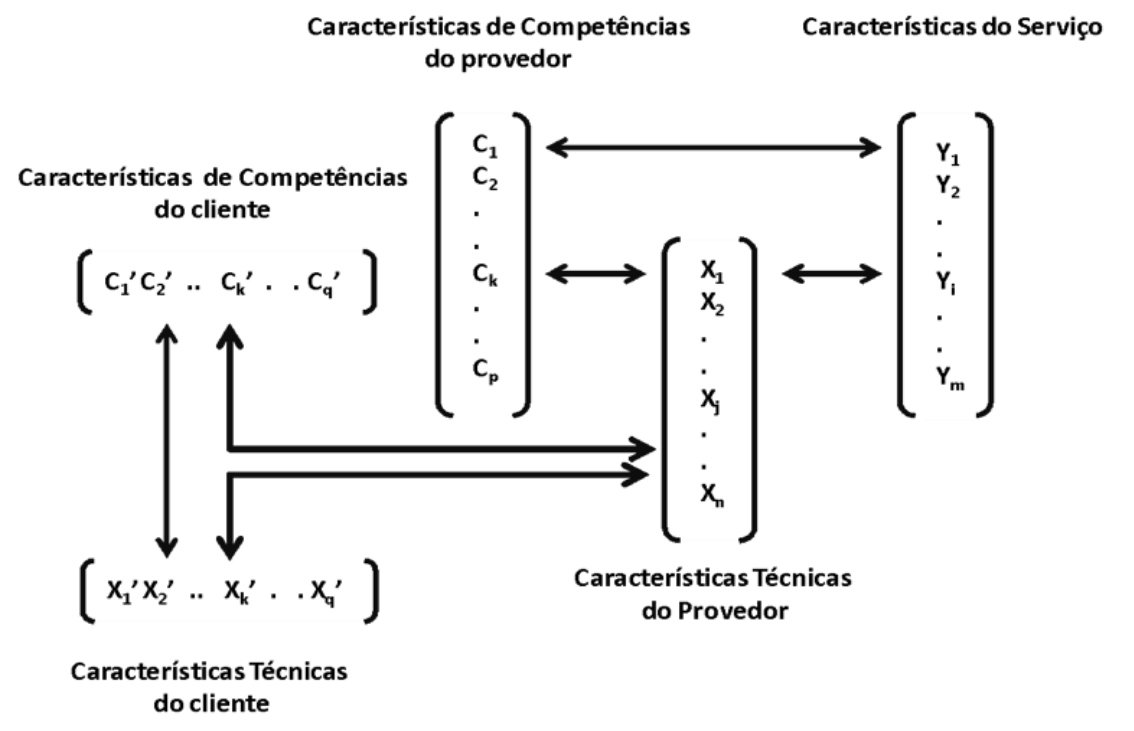

Figura 3: Representação de um serviço pelo modelo de características. Fonte: Adaptado de De Vries (2006).

A figura 4 ilustra um exemplo de aplicação do modelo de características a um serviço de transporte público de ônibus.

[C]

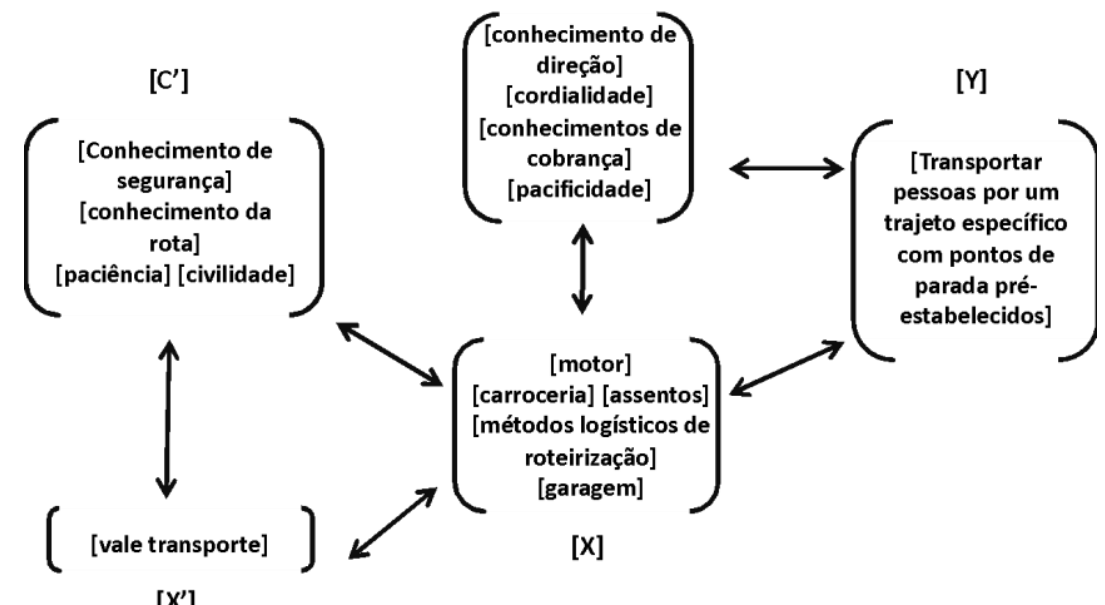

$\left[X^{\prime}\right]$

Figura 4: Caraterísticas e seus elementos de um serviço de ônibus para transporte público. Fonte: $O$ autor (2020)

Segundo Gallouj \& Weinstein (1997), a composição dos vetores de características e suas interrelações, mapeados nas figuras 3 e 4, podem proporcionar o surgimento de inovações seja pela evolução, eliminação, associação, ou dissociação de elementos. A figura 5 apresenta os tipos de inovações propostos pelos autores, bem como alguns exemplos. 


\begin{tabular}{|c|c|c|}
\hline Abordagem & Conceito de Mudanca & Foco da Intervencão \\
\hline Radical & $\begin{array}{l}\text { Há evoluções desconectadas em mais de uma } \\
\text { característica de um servico. }\end{array}$ & Serviço de transporte a cavalo para transporte a motor. \\
\hline Melhoria & $\begin{array}{l}\text { Não há alterações no serviço, apenas ganho de } \\
\text { qualidade em características }\end{array}$ & $\begin{array}{l}\text { Serviço de pagamento com cartão por senha para } \\
\text { pagamento com cartão por aproximação. }\end{array}$ \\
\hline Incremental & $\begin{array}{l}\text { Há adição ou substituição dos elementos das } \\
\text { características técnicas e/ou de servicos }\end{array}$ & $\begin{array}{l}\text { Serviço de telefonia móvel com franquia de dados sem } \\
\text { transferência para outras linhas para franquia de dados } \\
\text { com possibilidade de transferência para outras linhas. }\end{array}$ \\
\hline Adhoc & $\begin{array}{l}\text { Surge de maneira emergente e imprevisível pela } \\
\text { combinação de experiências e conhecimentos de todos } \\
\text { os beneficiários de um serviço em resposta a um } \\
\text { problema (novo ou antigo). }\end{array}$ & $\begin{array}{l}\text { Serviços de consultoria com soluções padronizadas } \\
\text { para consultoria com soluções customizadas. }\end{array}$ \\
\hline Recombinante & $\begin{array}{l}\text { Nasce da combinação de caraterísticas de produtos/ } \\
\text { serviços diferentes em busca de uma solução }\end{array}$ & $\begin{array}{l}\text { Serviços de seguros de vida para seguros de vida e } \\
\text { previdência. }\end{array}$ \\
\hline Formalizadora & $\begin{array}{l}\text { Não apresenta nenhum tipo de dinâmica de alteração, } \\
\text { apenas padroniza características nascentes em projetos } \\
\text { distintos como solução comercial. }\end{array}$ & $\begin{array}{l}\text { Serviços de consultoria com soluções customizadas } \\
\text { para soluções padronizadas. }\end{array}$ \\
\hline
\end{tabular}

Figura 5: Tipos de Inovações e seus exemplos. Fonte: O autor (2020)

\subsection{Oportunidade de melhoria}

O quadro conceitual de características é proposto nesta pesquisa para aprimorar a análise de das atividades mapeadas no diagrama PCN. Sendo assim, o método de mapeamento e identificação das atividades importantes e problemáticas para os beneficiários pelo método de Sampson (2015) é combinado com a visão de características de Gallouj \& Weinstein (1997), que habilita novas formas de melhorias pela reconfiguração minuciosas de suas características.

\section{Projetando serviços por meio da análise de características e competências}

\subsection{Procedimentos metodológicos}

O método foi definido com três fontes de coleta de dados (análise documental, observação não-participante e entrevistas) e seguiu os quatro critérios de Flick (2009) para pesquisas qualitativas, como o (1) não direcionamento do entrevistador; (2) a especificidade das perguntas balizadas pelos fluxogramas de processos de serviços, (3) o espectro das perguntas, abordando os assuntos necessários para pesquisa; e (4) a profundidade das respostas através de justificativas dos entrevistados e posterior relacionamentos entre os dados.

A figura 6 exibe a sequência das atividades para verificar os resultados da metodologia baseada na melhoria do método de Sampson (2015) com auxílio do método de Gallouj \& Weinstein 
(1997). Ressalta-se que o estudo empírico serve como um caso especial para se aplicar a ferramenta, fornecendo conteúdo para que, ao final, possa ser feita uma comparação entre o modelo atual dos serviços, pela efetividade da nova ferramenta construída.

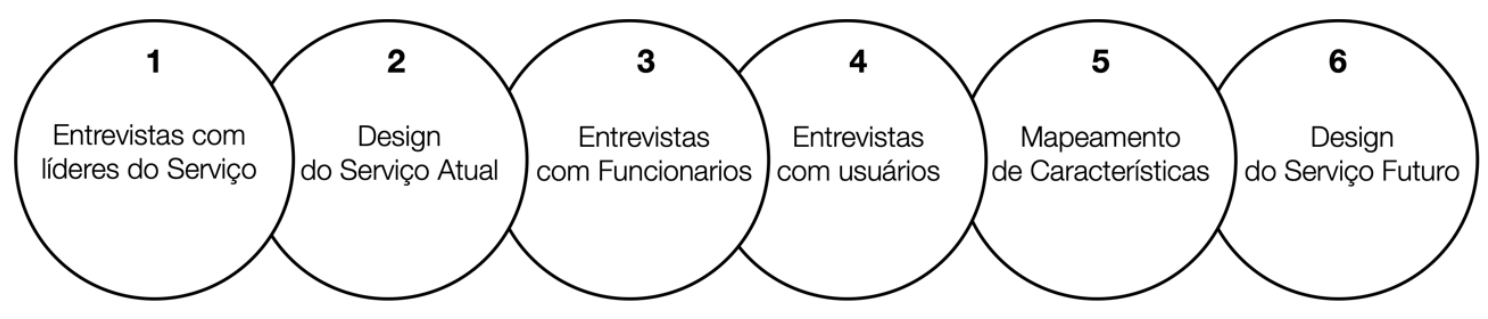

Figura 6: Etapas da estratégia de pesquisa. Fonte: $O$ autor (2020)

O método aplicado inicia-se com a entrevista dos responsáveis do serviço utilizando o roteiro de auditoria de Sampson (2015). Com os dados obtidos nessa primeira etapa constrói-se em seguida o PCN atual do serviço, o que equivale à segunda etapa. A terceira etapa inicia-se com a apresentação do PCN atual aos colaboradores da empresa prestadora do serviço, como recurso visual, para facilitar a entrevista utilizando as perguntas da figura 7 a fim de se identificar percepções de melhorias.

1. Quais atividades você desempenha na sua organização?

2. Você ou alguém da sua organização apoiou o projeto do processo de serviço de bar relacionadas a essas atividades?

3. Como você descreveria seu envolvimento no desenvolvimento do projeto do processo de serviço?

4. Qual seria a sua opinião caso você não tenha sido envolvido ou teve pouco envolvimento?

5. Com esse processo atual em execução, você acha que a organização teve seus objetivos alcançados?

6. Qual parte do processo que, em sua opinião, conseguiria atender às necessidades da organização?

7. Do momento em que você começou a atuar na sua ocupação até o presente momento aconteceu alguma mudança na operação em busca de melhorias?

8. Houve alguma parte do processo planejado que tenha sido adaptada por você durante sua execução devido a alguma circunstância da organização?

9. Você tem algum documento em que esteja registrado como transcorre o processo?

10. Existem outras pessoas que participaram da execução do processo que você acha interessante que fossem entrevistadas?

Figura 7: Questionário para mapeamento de características do processo de musculação. Fonte: $O$ autor (2018) 
A quarta etapa consiste na entrevista com usuários através do questionário da figura 8, fornecendo os dados necessários para se mapear em seguida como quinta etapa as características e competências do serviço, com vistas a um novo design, baseado em novas atividades derivadas das percepções do usuário. O novo design é a última etapa do método proposto e registra o novo processo pela notação PCN, comunicando quais características influenciam na execução das atividades.

1. Como você acha que o processo do serviço poderia melhorar?

2. Quais ações você toma para reduzir alguma sensação negativa que o processo provoca?

3. Há alguma contribuição a ser feita para o projeto do processo?

4. Quais seriam os benefícios se houvesse a implementação dessa percepção?

5. Para que essas melhorias fossem executadas, o que em sua opinião teria que ser feito na operação do serviço?

Figura 8: Questionário para mapeamento de características do processo de musculação para consumidor. Fonte: $\mathrm{O}$ autor (2018)

\subsection{PCN atual do serviço e sua percepção de valor}

A academia escolhida para esta pesquisa funciona há pouco mais de dez anos. Um total de sete pessoas foram entrevistadas (três alunos, o proprietário, a gerente e dois instrutores da academia) e dez alunos aleatórios foram observados durante a execução das séries de exercícios. As entrevistas ocorreram no próprio salão da academia e por meio de aplicativos de troca de mensagens, inicialmente com o proprietário e em seguida com os colaboradores, em dias diferentes. Os clientes entrevistados foram escolhidos de forma aleatória, apenas atendendo ao critério de tempo de usuários do serviço e frequência de treino.

A etapa de mapeamento do serviço tem como objetivo facilitar a conversa com os clientes por meio de uma ferramenta visual. O desenho do processo PCN do serviço atual teve sua primeira forma utilizando as informações originadas do proprietário e gerente da academia. Em seguida, os entrevistados (alunos e instrutores) foram questionados sobre quais atividades dos processos apresentavam valor no nível de satisfação, além de possíveis problemas que ocorrem no decorrer das atividades. Para tanto, o PCN do serviço atual foi exibido aos alunos e instrutores, e eles apontaram, na opinião deles, quais seriam as atividades com as devidas percepções de valor e custo, respectivamente. A figura 9 representa o PCN atual do serviço de musculação e pode ser lido da direita para esquerda, iniciando com as atividades do cliente do momento em que ele vai para academia, executa sua série de exercícios nos equipamentos, interage com os colaboradores e se ausenta da academia. $\mathrm{O}$ lado esquerdo representa as atividades do provedor para suportar as atividades com o cliente. 


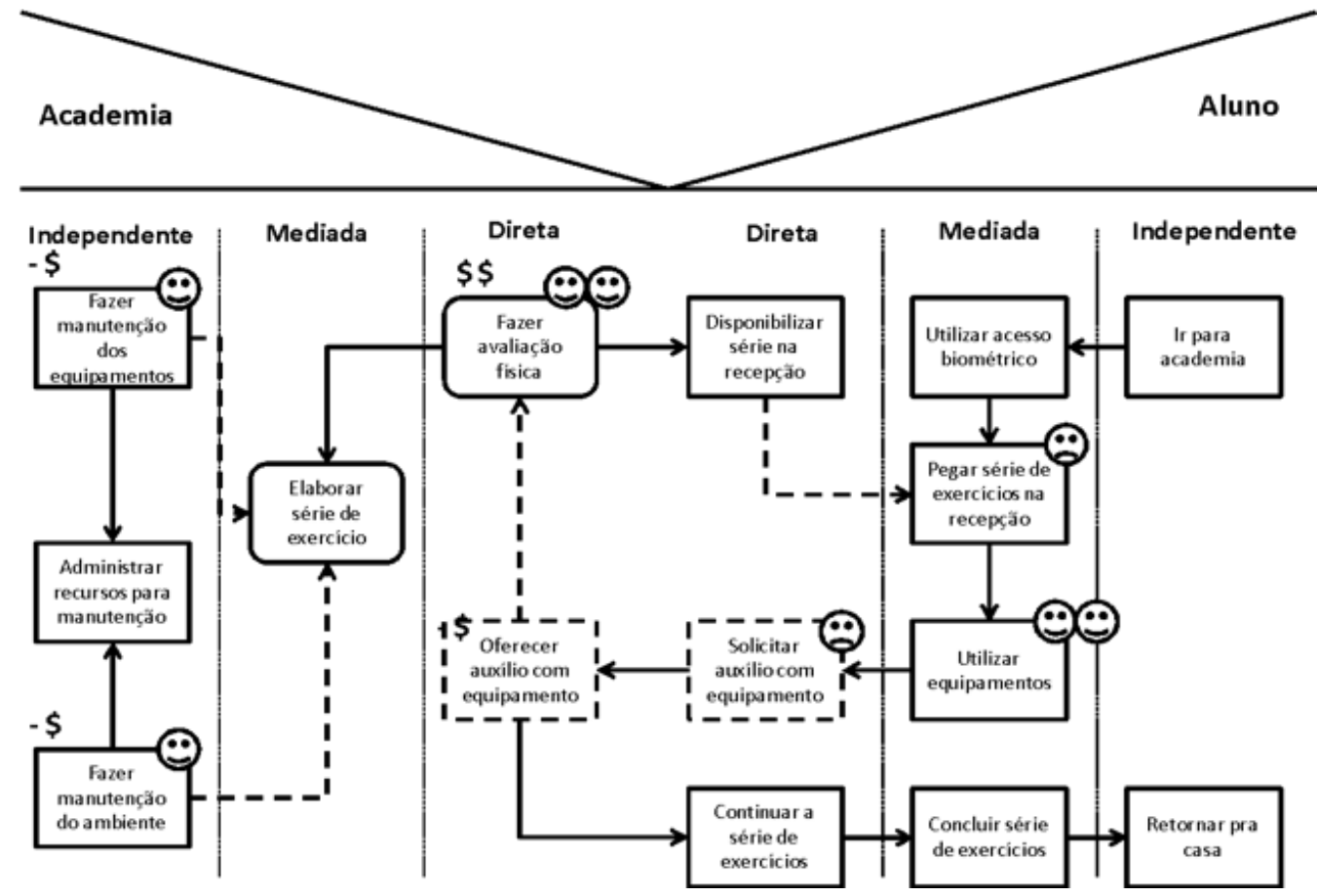

Figura 9: PCN do Serviço de Musculação e suas percepções. Fonte: $O$ autor (2018)

\subsection{O modelo de características do serviço de musculação}

O modelo de características e competências de Gallouj \& Weinstein (1997) surge nesta etapa do estudo de campo como uma ferramenta de análise complementar do serviço. O processo de serviço é interpretado por um ponto de vista alternativo, através de observações e entrevistas utilizando os roteiros das figuras 7 e 8 orientados ao entendimento de como as atividades são executadas pelos entrevistados. Com as respostas, construiu-se o modelo de características e competências que compõem o processo. A figura 10 exibe o resultado obtido descrevendo, da direita para a esquerda, a característica do serviço [Y], como ganho de massa muscular ou perda de peso; a característica técnica do provedor $[\mathrm{X}]$, com os equipamentos de exercícios, métodos de avaliação e sistemas de informação; a competência do provedor [C], com conhecimentos de educação física dos provedores; a característica do cliente [C], com as habilidade e conhecimentos necessários que os clientes precisam para fazer os exercícios; e a característica técnica do cliente $\left[\mathrm{X}^{`}\right]$, com a vestimenta necessária para fazer exercícios. 
$\left[C^{\prime}\right]$

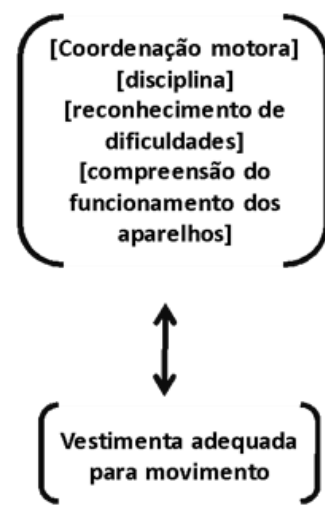

$\left[x^{\prime}\right]$
[C]

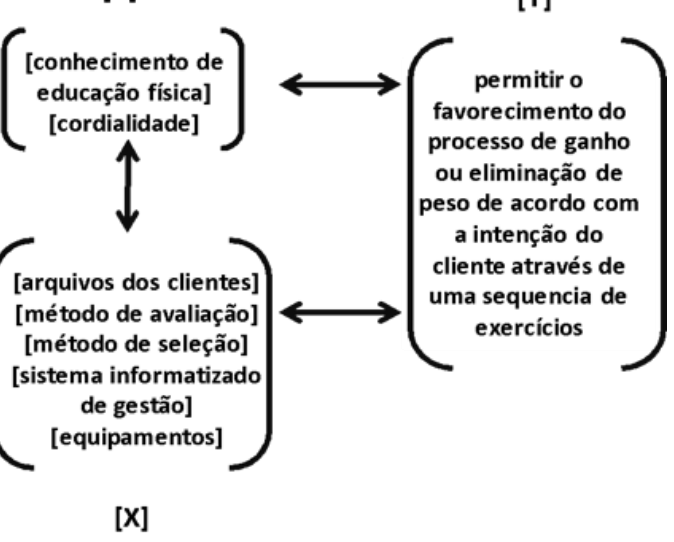

Figura 10: Características do processo de serviço de musculação atual. Fonte: $O$ autor (2018)

A segunda parte do estudo ainda se baseia nas entrevistas a partir da percepção de cada entrevistado e nas perguntas direcionadas a satisfação e percepções de melhoria do processo atual. A figura 11 apresenta os novos elementos de característica do serviço [Y], com ganho de massa muscular ou perda de peso pelo crossfit e treinos pagos por dia; a característica técnica do provedor $[\mathrm{X}]$, com equipamentos de crossfit e métodos de avaliação de desempenho; a competência do provedor $[\mathrm{C}]$, com conhecimentos de gestão financeira; a característica do cliente [C'], com entendimento de uso de aplicativos; e a característica técnica do cliente [X'], com smartphones.

[C']

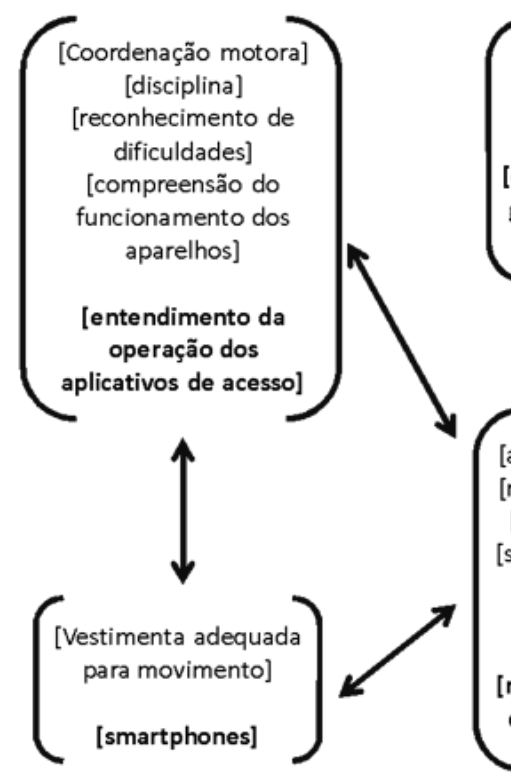

$\left[x^{\prime}\right]$ [c]

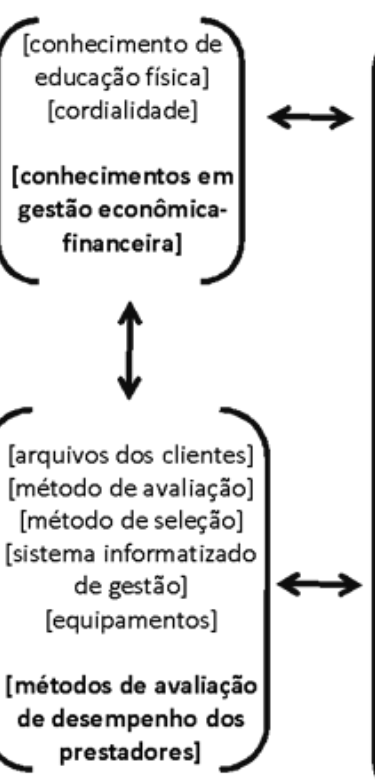

[Y]

permitir o favorecimento do processo de ganho ou eliminação de peso de acordo com a intenção do cliente através de uma sequencia de exercícios]

[Proporcionas aos alunos equilíbrio, agilidade, velocidade, potência, força, resistência muscular e cardiorrespiratória através do crossfit]

[Oferecer treinamentos para ganho de massa muscular e perda de peso de acordo com o objetivo

e tempo de cada aluno]

[Oferecer planos de pagamentos relacionados aos dias utilizados]

Figura 11: Características do processo de serviço de musculação futuro. Fonte: $O$ autor (2018) 
Os vetores definidos na figura 11 são o início da próxima etapa, em que as novas características e competências impactarão na criação ou modificação de atividades no diagrama PCN do serviço atual.

\subsection{O projeto do PCN de serviço de musculação futuro}

Seguindo o diagrama PCN de percepção de valor e custo, além dos vetores de características e competências para o futuro, foi possível subsidiar a criação do novo processo de serviço. Com os dados coletados, novas atividades foram criadas que eliminaram algumas atividades anteriores. Pode-se identificar na figura 12 todas as mudanças propostas em comparação com o processo anterior.

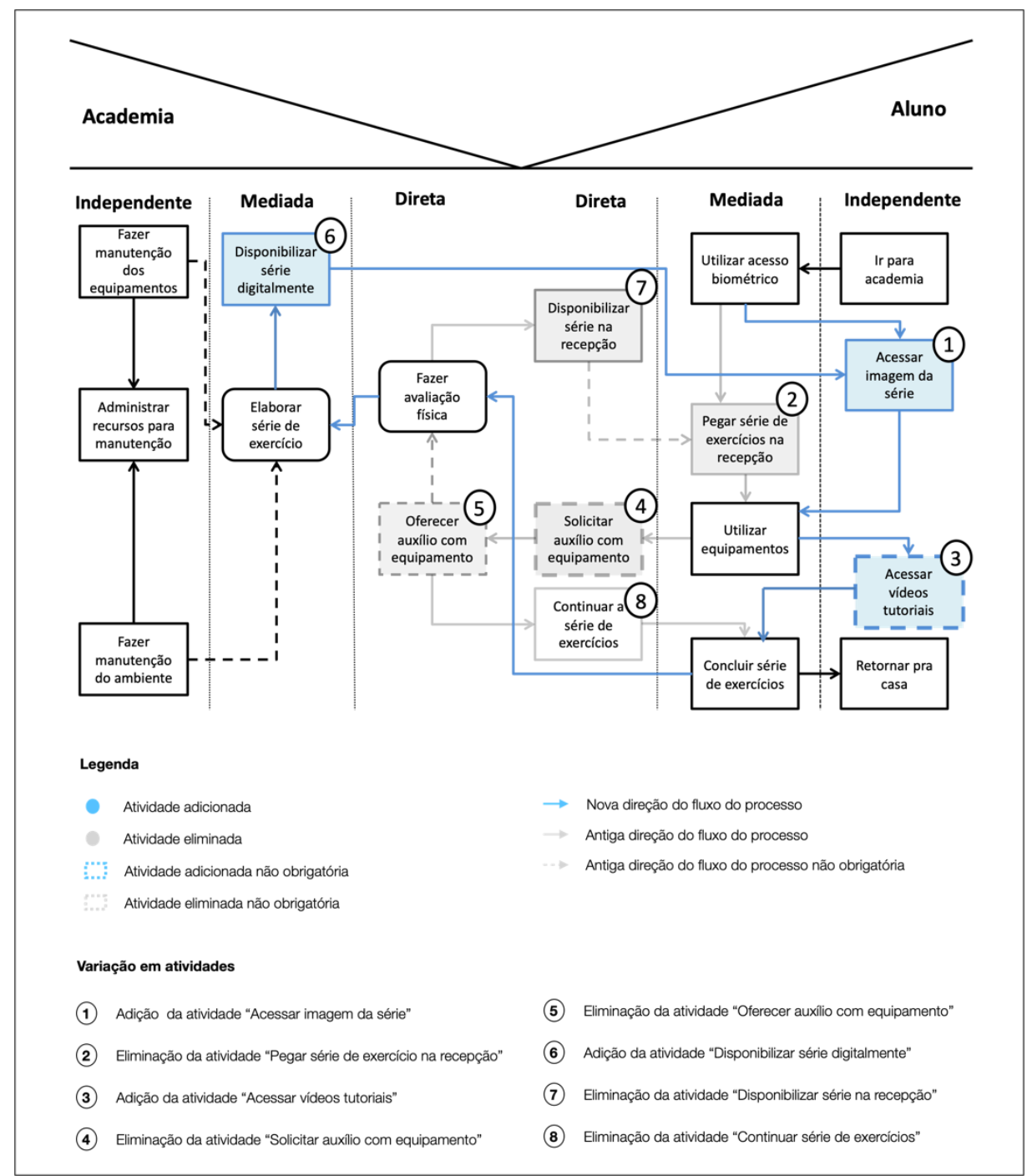

Figura 12: Novo PCN proposto para serviço de musculação. Fonte: O autor (2018) 
A figura 13 representa a nova versão do diagrama PCN do serviço de musculação. Sendo uma ferramenta de apoio visual ao planejamento de serviços, concluiu-se que o modelo de características e competências de Gallouj \& Weinstein (1997) também poderia ser representado no modelo PCN final dos processos apresentados. A aplicação dessa notação facilita a identificação das características e competências reconhecidas como diferenciais de melhoria da sua operação, além de sinalizar quais características são importantes para a operação do serviço atual.

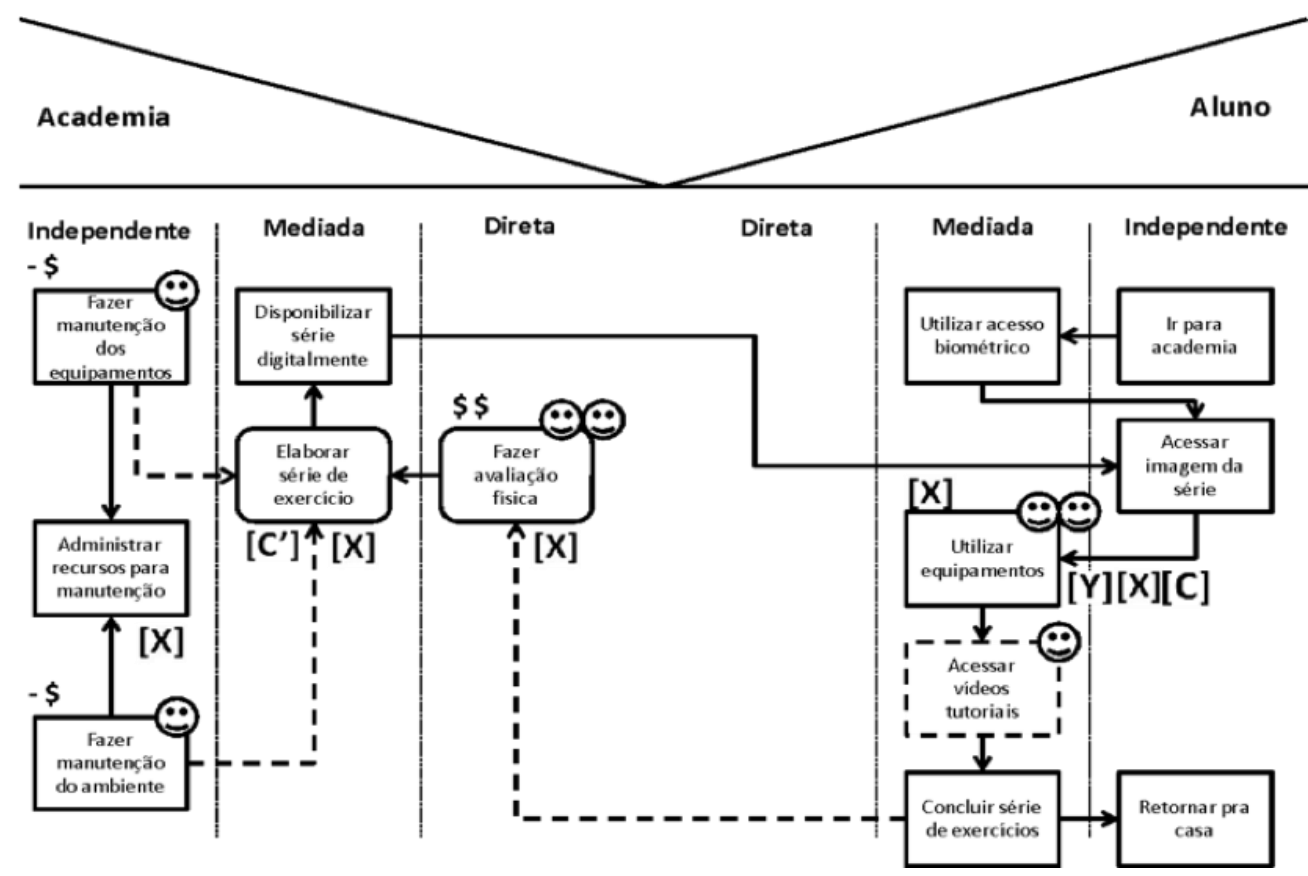

Figura 13: Novo PCN proposto para serviço de musculação. Fonte: O autor (2018)

Verificando a figura 13, nota-se que as características e competências do novo processo são indicadas próximas às atividades em que nascem. Da esquerda para a direita, na atividade "elaborar série de exercícios", estão localizados dois símbolos: um de característica técnica do provedor $[\mathrm{X}]$, relacionado ao método para criação de série customizada; e outro para uma competência do cliente [C'], relacionada ao conhecimento sobre educação física. Verifica-se ainda o caso da atividade "Utilizar equipamentos", que apresenta três símbolos relativos a: uma característica do serviço nova [Y], referente ao crossfit; uma característica técnica do provedor [X], relativa aos equipamentos do crossfit; e, por último, uma competência do provedor [C], atrelada aos conhecimentos necessários para a prática da modalidade.

Percebe-se que a melhoria no diagrama proporciona visões particulares quando explicita quais são as características e competências importantes para a realização da atividade e que impactam na melhoria de sua execução. Por essa conclusão, identifica-se que a notação é uma forma complementar ao quadro conceitual de Sampson (2015), descrevendo visualmente as informações que estavam antes implícitas no projeto e promovendo a comunicação pictórica para todos os responsáveis por sua execução. 


\section{Conclusão}

A contribuição desta pesquisa para o design de serviço está na proposição de uma metodologia que coloca os beneficiários genéricos e específicos como fontes legítimas de ideias, devido ao fato de utilizarem e produzirem o serviço. Pode-se dizer ainda que essa contribuição agrega mais um modo de se abordar tecnicamente um serviço, ou seja, a metodologia leva em consideração a forma de se planejar uma cadeia de serviços eficiente, organizando as atividades, verificando o que realmente é percebido como valor pelo consumidor e, ao mesmo tempo, evitando custos para organização de atividades que supostamente agregam valor às suas partes interessadas.

Admitindo-se a limitação da amplitude do estudo de caso, é importante que fique a sugestão para pesquisas futuras, aplicando a metodologia proposta em outras organizações similares às trabalhadas neste estudo empírico. O objetivo desta sugestão é obter mais dados, a fim de se realizar um cruzamento de informações em busca de novas criações de inovação. É sugerido também que o viés relativo às questões higiênico-sanitárias e de biosseguranças, tão prementes no atual contexto, seja abordado futuramente, a fim de que se considere no design as normas técnicas sobre esses assuntos e como estão impactando a experiência dos clientes.

Quanto à execução da metodologia, o viés econômico-financeiro não foi abordado nessa pesquisa. A limitação relacionada a esse fato é o acesso restrito a esse tipo de informação por parte das organizações. Sugere-se que essa metodologia seja empregada novamente utilizando um estudo de custo-benefício das melhorias, verificando a viabilidade financeira e grau de atendimento aos requisitos dos beneficiários para serem colocadas em prática.

Finalmente, sugere-se também para uma nova pesquisa a aplicação dessa metodologia para um serviço que ainda não está em operação, com o objetivo de se analisar o potencial desse serviço para a realização de um primeiro projeto, em que pudesse ser testado utilizando outras técnicas de design de prototipação de experiências.

\section{Agradecimentos}

O presente trabalho foi realizado com apoio da Coordenação de Aperfeiçoamento de Pessoal de Nível Superior - Brasil (CAPES) - Código de Financiamento 001.

This study was financed in part by the Coordenação de Aperfeiçoamento de Pessoal de Nível Superior - Brasil (CAPES) - Finance Code 001.

Agradeço também à Escola Superior de Desenho Industrial da Universidade do Estado do Rio de Janeiro, em especial aos professores Fernando Del Caro Secomandi e André Ribeiro de Oliveira, pelas aulas e conhecimentos transmitidos que recebi durante meu Mestrado Acadêmico em Design, os quais foram essenciais para elaboração desse trabalho retirado da Dissertação homônima. 


\section{Referências}

ALT, A. \& PINHEIRO, T. Design thinking Brasil: empatia, colaboração e experimentação para pessoas, negócios e sociedade. Rio de Janeiro. Editora Elsevier. 2010.

BAEK, J.S.; KIM, S.; PAHK, Y. \& MANZINI, E. A sociotechnical framework for the design of collaborative services. Design Studies.Vol 55. N ${ }^{\circ}$ C. 2018.

BATE, P. \& ROBERT, G. Bringing user experience to healthcare improvement: The concepts, methods and practices of experience-based design. 118-154. Radcliffe Publishing. Oxford. 2007.

BITNER, M. The impact of Physical Surrondings on Customers and Employees. Journal of Marketing, Vol. 56. N. 2. 1992.

BITNER, M. et al. Service Blueprinting: A Practical Tool for Service Innovation. Arizona State University, 2007.

BLAIKE, N. Designing Social Research. 2a Edição. 2000.

CARVALHO, L. \& GOODYEAR, P. Design, learning networks and innovation. Design Studies. Vol 55. $\mathrm{N}^{\circ}$ C. 2018.

CIPOLLA, C. \& MANZINI, E. Relational Services. 22:45-50. Know Techn Pol. 2009.

DATASEBRAE. Qual é a participação dos setores da economia no PIB?. Disponível em 14/04/2018: http://datasebrae.com.br/pib/

DE VRIES, E. J. Innovation in Services in Networks of Organizations and in the Distribution of Services. Research Policy, v. 35, n. 7, p. 1037-1051, set. 2006.

DELAUNEY, J.C. \& GADREY, J. The terciary sector and post-industrial society. IN: Delaunay, J.C. \& Gadrey, J. Service in Economic Thought - Three Centuries of debate. Vol. 3. França. PP 75- 101. 1992.

EDGETT, S. The traits of successful new service development. IN: Journal of Services Marketing. p. 40-49, vol. 8, 1994.

EICHENTOPF, T.; KLEINALTENKAMP, M. \& STIPHOUT, J.V. Modelling customer process activities in interactive value creation. IN: Journal of Services Management. p. 650663, vol. 22, $\mathrm{N}^{\circ}$ 5. 2011.

FELISMINO, A. \& SECOMANDI, F.D.C. Um estudo comparativo de fluxogramas de processos de serviços. Anais do $2^{\circ}$ Simpósio de Pós-graduação em Design da ESDI. Rio de Janeiro. 2016.

FLICK, U. Introdução à Pesquisa Qualitativa. $3^{\text {a }}$ Edição. Editora Bookman. Porto Alegre. 2009.

FLIESS, S. \& KLEINALTENKAMP, M. Blueprinting the service company Managing service processes efficiently. IN: Journal of Business Research. p. 392-404. 2004.

GALLOUJ, F \& SAVONA, M. Innovation in services: a review of the debate and a research agenda. J evol econ. 2009.

GALLOUJ, F \& TOIVONEN, M. Elaborating the characteristics-based approach to service innovation: making the service process visible. University of Lile, 1, Clersé. 2009.

GALLOUJ, F \& WEINSTEIN, O. Innovation in services. Research Policy. Elsevier. 1997.

IBGE. Pesquisa Nacional por Amostras de Domicílio continua. 2016.

ILLERIS, S. The Nature of Service. IN: Illeris, S. The handbook of service industries. Rio de Janeiro. PP 19- 33. 
JORGE, G. A. \& MIYAKE, D. I. Estudo comparativo das ferramentas para mapeamento das atividades executadas pelos consumidores em processos de serviços. Revista Production. 2014.

LANCASTER, K.J. A New Approach to consumer theory. The Journal of political economy. Vol 74. N.2. Chicago Journals. 1966.

LOVELOCK, C. \& WRIGHT, L. Serviços: Marketing e Gestão. $1^{\text {a }}$ Edição. $7^{\text {a }}$ Tiragem. Editora Saraiva. São Paulo. 2006.

MERONI, A. Creative communities: People inventing sustainable ways of living. Edizione POLI. Design. Milano. 2007.

PATRICIO, L.; CUNHA, J. F.; FISK, R.P. \& CONSTANTINE, L. Multilevel Service Design From Customer Value Constellation to Service Experience Blueprinting. In: Journal OF Service Reaserch. P180-200. 2011.

REASON, B.; LOVLIE, L. \& FLU, M.B. Service Design for business - A Practical guide to optimizing the customer experience. $1^{\text {a }}$ Edição. Willey. 2016.

SAMPSON, S.E. Essentials of Service Design and Innovation. $4^{\text {a }}$ Edição. Marriot School of Management. 2015.

SAMPSON, S.E \& FROEHLE. C. M. Foundations and Implications of a Proposed Unified Services Theory. Production and Operations Management. Production and Operations Management Society. Vol 15. 2006.

\section{Sobre os autores}

\section{Alan Felismino da Silva}

Mestre em Design (2018) pela Esdi/Uerj. Especialista em Gestão de Projetos (2017) e Engenheiro de Produção (2014) pela Uerj. Atuou como consultor de pesquisas em design de produtos e serviços em startups, incubadoras de empresas de base tecnológicas, empresas públicas e multinacionais. Atualmente é Doutorando em Engenharia de Produção pela UFRJ e trabalha como Service Designer e Pesquisador de Experiência do Usuário.

amino@coppe.ufrj.br

\section{Fernando Del Caro Secomandi}

Possui graduação em Desenho Industrial pela Escola Superior de Desenho Industrial (ESDI) da Universidade do Estado do Rio de Janeiro (UERJ), mestrado em Strategic Product Design e doutorado em Design, ambos com distinção (cum laude), pela Delft University of Technology, Holanda. Atualmente, é Professor Adjunto do Departamento de Projeto de Produto da ESDIUERJ.

fsecomandi@esdi.uerj.br

\section{André Ribeiro de Oliveira}

Possui graduação em Engenharia Eletrônica pela Universidade Federal do Rio de Janeiro, mestrado e doutorado em Engenharia de Produção pela mesma instituição com área de concentração em Gestão e Inovação. Atualmente é Professor Associado do Departamento de Engenharia Industrial da Universidade do Estado do Rio de Janeiro e do Programa de PósGraduação em Design da Escola Superior de Desenho Industrial da mesma instituição.

andre.ribeiro@eng.uerj.br 